\title{
International control of neutron calibration measurements
}

\author{
Horst Klein ${ }^{*}$ \\ Physikalisch-Technische Bundesanstalt (PTB) \\ Bundesallee 100, 38116 Braunschweig, Germany \\ E-mail: horst.klein@ptb.de
}

National metrology institutes (NMI) keep the national primary standards for all SI units and for some derived quantities required for the measurement of ionising radiation. In case of neutron measurements, the basic quantities are the total emission rate of sources and the (spectral) fluence rate.

Only a few NMI's or their associated laboratories are world-wide engaged in neutron measurements and regularly compare their primary standards in key comparisons organised by CCRI(III), the section III of the consultative committee for ionising radiation CCRI of CIPM (international committee for weights and measures). However, calibration measurements are accepted in some countries only if the measurement is traceable to their national primary standard even if the underlying procedure is supported by international comparisons.

In order to overcome these restrictions, the leading NMI's recently signed a Mutual Recognition Arrangement (MRA) which states that the calibrations of those laboratories for which the applied calibration measurement capability has been internationally approved will be accepted world-wide. Regional metrology organisations (RMO), in co-operation with the international bureau for weights and measures (BIPM), jointly organise the approval of submitted CMC's to confirm compliance with the agreed service categories and rules for specifying the CMC's. Provided these specifications are supported by successful participation in comparison exercises, the CMC's and the associated degree of equivalence are published in the key comparison data base (KCDB, parts $\mathrm{B}$ and $\mathrm{C}$ ) on the BIPM webpage. Calibrations performed according to approved CMC's are then accepted world-wide.

International Workshop on Fast Neutron Detectors

University of Cape Town, South Africa, April 3 - 6, 2006

\footnotetext{
${ }^{*}$ Speaker (retired, present address: Amselfeld 4e, 38179 Schwülper, Germany, email: urkle@t-online.de)
} 


\section{Introduction}

Experiments with neutrons require well specified neutron fields and detector systems. The total neutron emission rate and the neutron fluence (rate) are basic quantities for the characterisation of neutron sources and fields. Best possible accuracy is required for the determination of cross sections for neutron scattering and neutron-induced reactions, in particular if reference standards are established. For example, the quality of Monte-Carlo simulations of neutron interactions with matter (shielding problems, detector response, etc.) chiefly depends on the quality of the input data, in particular neutron cross sections. In addition, a sensitivity analysis requires a reliable evaluation of the uncertainties including correlations. Lowest uncertainties are achieved for the total cross sections which are determined as the flux attenuation of a well collimated neutron beam. While these measurements do not require the specification of the neutron detection efficiency of the detector system used, the energydependent response of the neutron detector must be known, at least on a relative scale, for the analysis of elastic and inelastic scattering experiments. Some measurement techniques permit the determination of cross sections of neutron-induced reactions or activation relative to better known reference cross sections. In general, however, the spectral neutron fluence rate must be specified in absolute scale for these cross section measurements and for the calibration of neutron sensitive devices.

The energy dependent detection efficiency of neutron detectors or the response matrix of neutron spectrometers must be known in a wide energy range, partially ranging from $\mathrm{meV}$ (thermal distribution) to some hundreds of $\mathrm{MeV}$, i.e. over more than 11 orders of magnitude. Besides a few exceptions, e.g. multisphere spectrometers and ${ }^{235} \mathrm{U}$-fission detectors, most neutron detector systems cover only a limited energy range. They are usually characterised by combining theoretical investigations, chiefly Monte Carlo simulations to account for the complexity of the neutron interaction with the detector assembly, and experimental methods, either by referring to evaluated standard cross sections or by particular absolute methods directly traceable to SI units.

Some national metrology institutes (NMI) or associated laboratories provide various calibration measurement capabilities (CMC) for this purpose. These CMC's are listed in part $\mathrm{C}$ of the key comparison data base $(\mathrm{KCDB})$ on the webpage of the BIPM (international bureau for weights and measures) in Sevres (www.bipm.org) after international approval according to the mutual recognition arrangement (MRA) signed in 1999 by the leading NMI's.

The basic quantities are defined in the next section. A discussion regarding the international co-operation of the consultative committee for ionising radiation (CCRI), in particular Section III for neutron measurements, and regional metrology organisations (RMO) for approval and dissemination of CMC's is then provided. Finally, comments are made regarding completed and currently active international comparisons which provide a degree of equivalence for supporting the specification of particular calibration services. 


\section{Basic quantities for neutron measurements}

Sealed radionuclide or accelerator-based neutron sources and filtered reactor beams are employed for neutron calibration measurements according to international recommendations, e.g. standard ISO 8529 part 1 [1]. Sources and fields are carefully characterised for their emission and fluence rate, respectively.

\subsection{Emission rate and anisotropy}

Sealed radionuclide neutron sources are commonly based on prompt fission $\left({ }^{252} \mathrm{Cf}\right)$ and $(\gamma, n)$ - or $(\alpha, n)$ - reactions $(\operatorname{Ra} / \operatorname{Be}(\gamma, n), \operatorname{Sb} / \operatorname{Be}(\gamma, n), \operatorname{Am} / \operatorname{Be}(\alpha, n), \operatorname{Am} / \operatorname{B}(\alpha, n))$. The basic quantity of such sources is the total neutron emission rate $\mathrm{d} B / \mathrm{d} t$, which is determined by moderation in manganese or water baths and measurement of the activation produced by the subsequent neutron capture reactions ${ }^{55} \mathrm{Mn}\left(\mathrm{n}_{\mathrm{th}}, \gamma\right)$ or ${ }^{197} \mathrm{Au}\left(\mathrm{n}_{\mathrm{th}}, \gamma\right)$, respectively. These methods are traceable to the primary standards for the measurement of radioactivity in terms of Becquerel. Standard uncertainties for these methods of (0.2-0.5) \% are typically evaluated according to GUM [2] and must be confirmed by comparison exercises.

Since most radio-nuclide sources exhibit a non-isotropic neutron emission due to their finite size and double encapsulation (for safety reasons), the emission rate and the spectral fluence are angular dependent. Hence, the anisotropy of emission and spectral fluence rates, $\mathrm{d}^{2} B / \mathrm{d} t \mathrm{~d} \Omega$ and $\mathrm{d}^{3} \Phi / \mathrm{d} E \mathrm{~d} t \mathrm{~d} \Omega$, respectively, must also be specified.

\subsection{Angular and energy dependent fluence rate}

Neutron fields suited for calibration services are preferentially produced with particle accelerators through selected $(\mathrm{p}, \mathrm{n})$ - or $(\mathrm{d}, \mathrm{n})$-reactions with Li-, D- or T-loaded targets in order to provide almost mono-energetic neutron fields (see ISO 8529 part 1). These calibration fields are required for the investigation of the energy-dependent response of neutron sensitive devices. The (point) sources must be characterised for their angular and energy dependent fluence rate $\mathrm{d}^{3} \Phi / \mathrm{d} E \mathrm{~d} t \mathrm{~d} \Omega$. Complementary to accelerator-based sources of mono-energetic neutrons, various filtering of the primary fission or moderated neutron fields at research reactors is applied to cover the energy range from a thermal distribution to almost mono-energetic neutron beams with energies up to $144 \mathrm{keV}$ by means of difference-filter techniques (see ISO 8529 part 1).

Various methods can be applied to determine the spectral neutron fluence (rate), chiefly time-of-flight spectrometry or unfolding of pulse-height spectra. The neutron detection with reference systems is chiefly based on nuclear reactions for which the cross sections can be regarded as standards (see Table 1). Absolute calibration methods directly traceable to SI-units take advantage of the unique correlation of the neutron with the associated charged particle method (TCAP), but can be applied for selected energies only. In special cases, the neutron emission can be related to the activity of the charged particles associated with the neutrons. The uncertainty budget is compiled and evaluated according to GUM [2] and the laboratories claim 
that uncertainties $<2.5 \%$ are achievable. An international approval is, however, required to confirm these statements in comparison exercises.

\begin{tabular}{|c|c|c|c|}
\hline Reaction & Q-value & Energy Range & Detector systems \\
\hline $\mathrm{H}(\mathrm{n}, \mathrm{n}) \mathrm{H}$ & & $1 \mathrm{keV}$ to $20(100) \mathrm{MeV}$ & PC, IC, RPT, SC \\
\hline${ }^{235} \mathrm{U}(\mathrm{n}, \mathrm{f})$ & $\sim 200 \mathrm{MeV}$ & $0.1 \mathrm{MeV}$ to $20 \mathrm{MeV}$ & FC, GIC \\
\hline${ }^{6} \mathrm{Li}(\mathrm{n}, \alpha) \mathrm{T}$ & $4.785 \mathrm{MeV}$ & Thermal to $0.1 \mathrm{MeV}$ & SS, SC, GIC \\
\hline${ }^{10} \mathrm{~B}(\mathrm{n}, \alpha)^{7} \mathrm{Li}^{*}$ & $2.792 / 2.31 \mathrm{MeV}$ & Thermal to $0.2 \mathrm{MeV}$ & PC $\left(\mathrm{BF}_{3}\right)$ \\
\hline${ }^{238} \mathrm{U}(\mathrm{n}, \mathrm{f})$ & $\sim 200 \mathrm{MeV}$ & $1.2 \mathrm{MeV}$ to $20 \mathrm{MeV}$ & FC, GIC \\
\hline${ }^{3} \mathrm{He}(\mathrm{n}, \mathrm{p}) \mathrm{T}$ & $0,764 \mathrm{MeV}$ & Thermal to $1 \mathrm{MeV}$ & SS, PC, GIC \\
\hline${ }^{197} \mathrm{Au}(\mathrm{n}, \gamma){ }^{198} \mathrm{Au}$ & & Thermal, 0.2 to $3.5 \mathrm{MeV}$ & Foil \\
\hline${ }^{12} \mathrm{C}(\mathrm{n}, \mathrm{n})^{12} \mathrm{C}$ & & $1 \mathrm{keV}$ to $2(5) \mathrm{MeV}$ & \\
\hline
\end{tabular}

Detector System Acronyms:

$\mathrm{PC}=$ proportional counter, $(\mathrm{G}) \mathrm{IC}=($ gridded $)$ ionisation chamber, $\mathrm{FC}=$ fission chamber, $\mathrm{RPT}=$ recoil proton telescope, $\mathrm{SS}=$ sandwich spectrometer, $\mathrm{SC}=$ scintillator, Foil = activation sample

Table 1: Nuclear data standards for neutron measurements

\section{International quality control}

The international committee for weight and measures CIPM is formed by 53 national metrology institutes of countries representing all five continents. Among other responsibilities, CIPM decides on the definition of SI units and is in charge of running the international bureau for weights and measures, BIPM, in Sevres, which, as the only international metrology laboratory, keeps the international standards for all SI units and some derived quantities. On request the BIPM is obliged to compare the national standards of the member states with their international standard. In this way a degree of equivalence is established. Due to an increase of comparisons with an increasing number of member states, this kind of quality control had to be reorganised.

Initiated by BIPM, 25 NMI's signed in 1999 a mutual recognition arrangement (MRA). Today, 35 NMI's essentially agree that calibration measurements must be accepted world-wide if the applied procedure ia internationally approved according to the MRA requirements.

All RMO's and BIPM agreed on service categories for ionising radiation and on the rules to specify CMC's. The calibration laboratory submits the CMC to his RMO for international approval. The most important precondition for acceptance of CMC's is that the specifications, in particular the stated uncertainties, are supported by a successful participation in comparison exercises.

Key comparisons of primary national standards, established for neutron metrology, are organised by section III of the consultative committee for ionising radiation, CCRI(III). Up to 20 NMI's or their associated laboratories participated in 8 key comparisons which were completed and published from 1970 to 1991 [3-11]. MRA requires repetition of such 
comparison exercises in periods of 10-20 years, depending on the quantity and the complexity of the service. Since CCRI(III) does not deal with all derived quantities of interest, e.g. ambient and personal dose equivalent, RMO's organise supplementary comparisons. BIPM regularly updates the key comparison data base $(\mathrm{KCDB})$ on their webpage with the results of comparison exercises (part B) and approved CMC's (part C).Currently 12 NMI's or associated laboratories form CCRI(III). These laboratories offer CMC's for selected quantities (see Table 2).

\begin{tabular}{|l|l|l|}
\hline \multicolumn{1}{|c|}{ Quantity } & \multicolumn{1}{|c|}{ Methods and Specifications } & \multicolumn{1}{|c|}{ Laboratories } \\
\hline $\begin{array}{l}\text { Neutron emission rate } \\
\text { and anisotropy }\end{array}$ & $\begin{array}{l}\text { Sealed radionuclide neutron } \\
\text { sources in Mn-bath, water-bath } \\
\text { or graphite moderator } \\
\text { (ISO 8529, part 1) }\end{array}$ & $\begin{array}{l}\text { CIAE, CMI, KRISS, LMNRI, } \\
\text { LNHB-LNE, NMIJ-AIST, NPL, } \\
\text { NIST, VNIIM }\end{array}$ \\
\hline Thermal neutron spectral fluence & $\begin{array}{l}\text { Thermal column of reactor or } \\
\text { moderated sources }\end{array}$ & $\begin{array}{l}\text { Beams: CIAE, NIST, NPL, PTB } \\
\text { Fields: IRSN-LNE, KRISS, } \\
\text { LMNRI-IRD, NMIJ-AIST, } \\
\text { VNIIM }\end{array}$ \\
\hline $\begin{array}{l}\text { Fluence(rate) of mono-energetic } \\
\text { neutrons }\end{array}$ & $\begin{array}{l}\text { Mono-energetic neutron fields, } \\
\text { 24 keV to 19 MeV } \\
\text { (ISO 8529, part 1) }\end{array}$ & $\begin{array}{l}\text { CIAE, (IRSN-LNE), NMIJ- } \\
\text { AIST, NPL, PTB, VNIIM }\end{array}$ \\
\hline $\begin{array}{l}\text { Fluence(rate) of quasi mono- } \\
\text { energetic neutrons }\end{array}$ & $\begin{array}{l}\text { Li(p,n)-reaction for 33, 45 and } \\
60 \text { MeV }\end{array}$ & PTB (at UCL) \\
\hline Spectral neutron fluence (rate) & Multisphere Spectrometer & CMI \\
\hline Ambient dose equivalent (rate) & $\begin{array}{l}\text { Calibration with radionuclide } \\
\text { neutron sources } \\
\text { (ISO 8529, parts 1-3) }\end{array}$ & $\begin{array}{l}\text { CIAE, CMI, KRISS, LMNRI- } \\
\text { IRD, IRSN-LNE, NMIJ-AIST, } \\
\text { NPL, NIST, PTB, VNIIM }\end{array}$ \\
\hline Personal dose equivalent (rate) & $\begin{array}{l}\text { Calibration on phantom with } \\
\text { radionuclide neutron sources } \\
\text { (ISO 8529, parts 1-3) }\end{array}$ & $\begin{array}{l}\text { CIAE, CMI, KRISS, LMNRI- } \\
\text { IRD, IRSN-LNE, NMIJ-AIST, } \\
\text { NPL, NIST, PTB, VNIIM }\end{array}$ \\
\hline
\end{tabular}

Neutron Metrology Laboratories:

CIAE/PRC-Beijing, CMI/Cz-Prague, IRSN-LNE/F-Cadarache, KRISS/Kr-Seoul, LNHB-LNE/F-Saclay, LMNRI-IRD/Br-Rio de Janeiro, NIST/USA-Gaithersburg, NPL/UK-Teddington, PTB/D-Braunschweig, SMU/Sk-Bratislava, VNIIM/Ru-St. Petersburg

(Note: IRMM/EU-Geel, a European research laboratory, does not offer CMC's)

Table 2: Calibration measurement capabilities of CCRI-member institutes

As listed in Table 3, CCRI(III) currently organises three key comparisons, namely:

- CCRI(III)-K8: determination of integral fluence and mean energy of a thermal neutron distribution. The response of a set of transfer-instruments has to be determined for an agreed reference distribution (protocol in discussion, start in 2006)

- CCRI(III)-K9.AmBe: determination of the emission rate of an Am/Be-source circulated among all participants (measurements completed, evaluation in progress)

- CCRI(III)-K10: determination of the fluence of mono-energetic neutrons from $144 \mathrm{keV}$ to 14.8 MeV. Instead of calibrating transfer instruments, for the first time all participants 
employed their primary standard (or calibrated transfer-standards) in the same field relative to a neutron monitor (evaluation completed and final report in progress).

The key comparison reference value and the degree of equivalence for each participant shall be determined according to an internationally agreed recommendation [12].

Those CMC's which cannot be traced back to the national primary standard cannot be confirmed by CCRI key comparisons. Instead, RMO's conduct supplementary comparison exercises with all laboratories, also from other RMO's, which offer the same calibration service on the basis of secondary standards traceable to the primary standard of other NMI's. Two currenly running EUROMET supplementary comparisons are also listed in Table 3, namely:

- EUROMET.RI(III)-S1: calibration of two neutron survey meters in terms of ambient dose equivalent (started in 2005)

- EUROMET.RI(III)-S2: determination of the fluence of mono-energetic neutrons from 15.5 $\mathrm{MeV}$ to $19 \mathrm{MeV}$ with three participants from Europe only. The same procedure as for CCRI(III)-K10 was applied (experiments completed, evaluation in progress).

Other RMO's started similar activities. It should be noted that details concerning MRA, $\mathrm{CMC}$ and $\mathrm{KCDB}$ are found on the webpage of BIPM at (www.bipm.org).

\begin{tabular}{|c|c|c|c|c|}
\hline Comparison & Quantity & Participants & Date & Status \\
\hline $\begin{array}{c}\text { CCRI(III)- } \\
\text { K8 }\end{array}$ & $\begin{array}{c}\text { Thermal neutron } \\
\text { (spectral) fluence }\end{array}$ & $\begin{array}{c}\text { CIAE, IRSN-LNE, LMNRI- } \\
\text { IRD, KRISS, NMIJ-AIST, } \\
\text { NIST, NPL, PTB }\end{array}$ & $\begin{array}{c}2006- \\
2009 ?\end{array}$ & $\begin{array}{c}\text { Protocol in } \\
\text { discussion }\end{array}$ \\
\hline $\begin{array}{c}\text { CCRI(III)- } \\
\text { K9.AmBe }\end{array}$ & $\begin{array}{c}\text { Emission rate of a } \\
\text { sealed neutron } \\
\text { source }\end{array}$ & $\begin{array}{c}\text { CIAE, CMI, KRISS, } \\
\text { LNHB-LNE, LMNRI-IRD, } \\
\text { NIST, NPL, VNIIM }\end{array}$ & $\begin{array}{c}1999- \\
2006\end{array}$ & $\begin{array}{c}\text { Measurements } \\
\text { completed, } \\
\text { evaluation }\end{array}$ \\
\hline $\begin{array}{c}\text { CCRI(III)- } \\
\text { K10 }\end{array}$ & $\begin{array}{c}\text { Fluence of mono- } \\
\text { energetic neutrons } \\
(0.144-14.6 \text { MeV) }\end{array}$ & CIAE, IRMM, NIST, \\
NMIJ-AIST, NPL, PTB, & $2001-$ & 2006 & $\begin{array}{c}\text { Final report in } \\
\text { progress }\end{array}$ \\
\hline $\begin{array}{c}\text { EUROMET. } \\
\text { RI(III)-S1 }\end{array}$ & $\begin{array}{c}\text { Neutron ambient } \\
\text { dose equivalent }\end{array}$ & $\begin{array}{c}\text { CIAE, CMI, IRSN-LNE, } \\
\text { NIST, NPL, PTB, SMU, }\end{array}$ & $2006-$ & $\begin{array}{c}\text { Measurements } \\
\text { started }\end{array}$ \\
\hline $\begin{array}{c}\text { EUROMET. } \\
\text { RI(III)-S2 }\end{array}$ & $\begin{array}{c}\text { Fluence of mono- } \\
\text { energetic neutrons } \\
(15.5-19 \mathrm{MeV})\end{array}$ & IRMM, NPL, PTB & $2004-$ & $\begin{array}{c}\text { Measurements } \\
\text { completed, } \\
\text { evaluation }\end{array}$ \\
\hline
\end{tabular}

Neutron Metrology Laboratories:

CIAE/PRC-Beijing, CMI/Cz-Prague, IRMM/EU-Geel, IRSN-LNE/F-Cadarache, KRISS/Kr-Seoul, LNHB-LNE/F-Saclay, LMNRI-IRD/Br-Rio de Janeiro, NIST/USA-Gaithersburg, NPL/UK-Teddington, PTB/D-Braunschweig, SMU/Sk-Bratislava, VNIIM/Ru-St. Petersburg

The pilot laboratory responsible to conduct and evaluate the exercise is underlined.

Table 3: Comparison exercises currently organised by CCRI(III) and EUROMET 


\section{Present status and future needs}

Depending on whether the current comparison exercises are successfully completed and the results including the degree of equivalence for each participant have been published in part $\mathrm{B}$ of KCDB, the CMC's are either supported or must be deleted from part C of KCDB.

There is, however, also a need for quality control of some unique CMC's. If only one NMI offers calibration service, e.g. for calibrations in quasi-mono-energetic neutron beams with energies between $20 \mathrm{MeV}$ and $70 \mathrm{MeV}$, and if laboratories active in another RMO provide the same fields, an RMO can issue an invitation for a joint comparison exercise. For this particular case, a set of ${ }^{235} \mathrm{U}$ - and ${ }^{238} \mathrm{U}$-fission chambers, prepared and characterised at Harwell laboratories, would be ideal transfer instruments [9]. Their neutron detection efficiency could be determined at 3-5 agreed energies, possibly for neutron energies ranging from $20 \mathrm{MeV}$ up to $200 \mathrm{MeV}$.

Another open question is the reliability of covariance matrices obtained in neutron spectrometry. Advanced theoretical models for the evaluation of the uncertainties must be checked by means of comparison exercises. An exercise performed with various multisphere detector systems in a simulated workplace field [13] did not yet include a thorough investigation of the uncertainty propagation.

Last, but not least, CCRI(III) and the corresponding working groups of all RMO's should inspect and compare evaluated cross sections of different libraries, in particular the standards needed for the characterisation of the primary standard instruments like the n-p scattering cross section for the recoil proton detection. The aim should be to agree on one data set. In any case, the data used must be clearly documented.

\section{Acknowledgement}

The author would like to thank all members of CCRI(III) and former CCEMRI(III) for a fruitful and successful collaboration in the field of neutron metrology in the last two decades. Valuable comments of Dr. Ralf Nolte and Dr. Marcel Reginatto on the manuscript are gratefully acknowledged.

\section{References}

[1] ISO 8529-1: Neutron reference radiation: Characteristics and methods of production, International Standards Organisation ISO, Geneva, 2001

[2] GUM: Guide to the expression of uncertainty in measurement, joint publication of ISO, IEC, OIML and BIPM, International Standards Organisation ISO, Geneva, 1993 and 1995 (corrected)

[3] E.J. Axton, Results of the intercomparison of the thermal neutron flux density unit (1966-1968), Metrologia 6 (1970) 25-?? 
[4] V.D. Huynh, International comparison of flux density measurements for mono-energetic fast neutrons, Metrologia 16 (1980) 31-49

[5] V.E. Lewis, International intercomparison of $d+T$ neutron fluence and energy using Niobium and Zirconium activation, Metrologia 20 (1984) 49-53

[6] H. Liskien, International fluence-rate intercomparison for $2.5 \mathrm{MeV}$ and $5.0 \mathrm{MeV}$, Metrologia 20 (1984) 55-59

[7] T.B. Ryves, International fluence-rate intercomparison for 144 and 565 keV neutrons, Metrologia 24 (1987) 27-37

[8] E.J. Axton, Intercomparison of neutron-source emission rates (1979-1984), Metrologia 23 (1986/87) 129-144

[9] D.B. Gayther, International intercomparison of fast neutron fluence-rate measurements using fission chamber transfer instruments, Metrologia 27 (1990) 221-231

[10] V.D. Huynh, BIPM neutron dosimetry comparison based on the circulation of a set of transfer instruments, Rad. Prot. Dosim. 44 (1992) 111-113

[11] R.S. Caswell, V.E. Lewis, Neutron measurement intercomparisons sponsored by CCEMRI, section III (neutron measurements), Radiat. Prot. Dosim. 44 (1992) 105-110

[12] M.G. Cox, The evaluation of key comparison data, Metrologia 39 (2002) 589-595

[13]D.J. Thomas, J.L. Chartier, H. Klein, O.F. Naitsmith, F. Posny, G.C. Taylor, Results of a large scale neutron spectrometry and dosimetry comparison exercise at the Cadarache moderator assembly, Radiat. Prot. Dosim. 70 (1997) 313-322 